\title{
OTIMIZAÇÃO DA PERFORMANCE DE CAVALOS/CAVALEIROS DE ENDURO ATRAVÉS DE TÉCNICAS DE MENSURAÇÃO DE ESTRESSE, TERMOGRAFIA E BIOMECÂNICA
}

\begin{abstract}
William M. Pitarello (IC), Daniella J. de Moura (PQ)
\section{Resumo}

O objetivo deste projeto foi otimizar a performance do cavaleiro/cavalo de enduro através de análises de estresse, biomecânicas e de temperatura de superfície corporal. O experimento foi realizado em um Haras na região de Campinas em treinamentos e provas de enduro. Um grupo de 5 cavalos Anglo Árabe foi avaliado assim como um grupo de 5 cavaleiros, sendo, cada cavalo para cada cavaleiro. As avaliações foram realizadas uma vez por semana, em um período de dois meses, totalizando 8 avaliações no período mais quente do dia, entre 13:00h e 15:00h. Tanto para cavaleiro como cavalos foram realizadas avaliação da temperatura de superfície antes e após o treino, assim como mensuração dos batimentos cardíacos e frequência respiratória dos cavalos. Os dados de temperatura de superfície dos cavalos e cavaleiros foram comparados por uma análise de comparação de médias avaliando a diferença entre os mesmos antes e após treino. A biomecânica do cavaleiro foi avaliada em um intervalo de $200 \mathrm{~m}$ durante $\mathrm{o}$ treino em comparada a padrões já existentes na literatura.
\end{abstract}

Palavras Chave: ambiência, zootécnica de precisão, biomecânica.

\section{Introdução}

A multidisciplinaridade da pesquisa é essencial para o avanço da ciência. Este estudo pretende unir pesquisas já realizadas na Faculdade de Engenharia Agrícola da Unicamp, relacionados ao aumento da performance de cavalos de enduro através da Termografia (1) com estudos a serem realizados junto a Faculdade de Ciências Aplicadas da Unicamp. No Brasil não existem praticamente estudos da interação cavalo/cavaleiro em condições de treinamento ou competição.

O objetivo deste projeto foi otimizar a performance do cavaleiro/cavalo de enduro através de análises de estresse, biomecânicas e de temperatura de superfície corporal

\section{Resultados e Discussão}

Observou-se com a realização do treino que a temperatura da superfície corporal média tanto do cavalo como do cavaleiro subiu em todas as partes do corpo que foram avaliadas. Não houve diferença significativa entre as partes do corpo avaliadas dos cavaleiros. Porem para o cavalo, a virilha foi a parte do corpo onde observou-se o maior aumento da temperatura corporal, significativamente diferente das demais temperaturas avaliadas.

Por outro lado, como era de se esperar, ouve um aumento nos batimentos cardíacos e frequência respiratória dos cavalos em média 22 e 14 pontos, respectivamente.

\section{Conclusões}

Foi possível encontrar uma correlação significativa entre a temperatura de superfície, a taxa respiratória e batimentos cardíacos do cavalo. A análise biomecânica permitiu que fosse proposta uma melhora na performance do conjunto cavalo-cavaleiro nas condições de treinamento.

\section{Agradecimentos}

Agradecemos ao CNPq e Pro Reitoria de Pesquisa da Unicamp pela bolsa concedida para a realização deste trabalho. Inserir aqui seu agradecimento e/ou informar a Instituição de fomento, se houver.

\footnotetext{
${ }^{1}$ Maia, A.P.A.; OLIVEIRA, S. R. M. ; MOURA, D. J. ; SARUBBI, J ; Vercellino, R.A.; MEDEIROS, B. B. L. ; Griska, P.R. . A Decisiontree-based model for evaluation of thermal comfort of horses. Scientia Agricola (USP. Impresso), v. 70, p. 377-383, 2013.
} 